
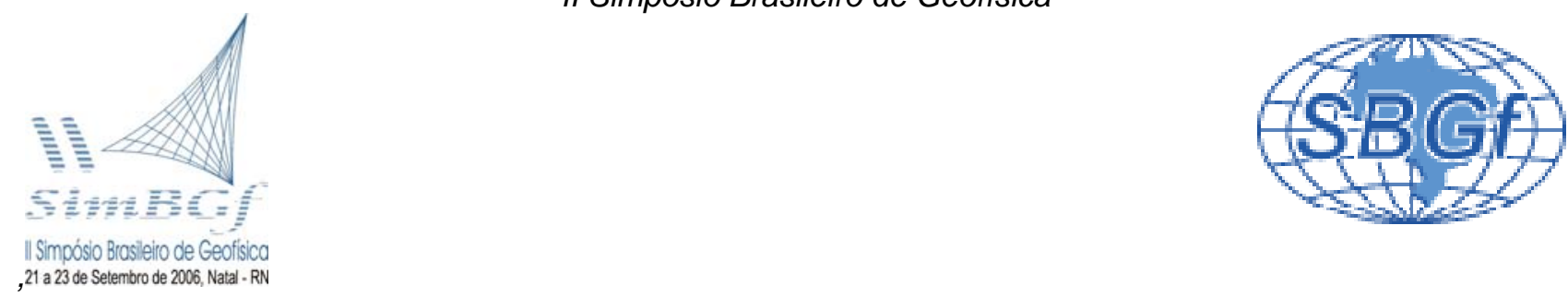

\title{
Processamento Sísmico pelo Método CRS
}

Martin Tygel, Fernando Gamboa e Lucas Freitas - Laboratório de Geofísica Computacional, UNICAMP

Copyright 2006, SBGf - Sociedade Brasileira de Geofísica

Este texto foi preparado para a apresentação no II Simpósio de Geofísica da Sociedade Brasileira de Geofísica, Natal, 21-23 de setembro de 2006. Seu conteúdo representa a opinião da SBGf ou de seus associados. E proibida a reprodução total ou parcial deste material para propósitos comerciais sem prévia autorização da SBGf.

\section{Resumo}

O método CRS (Common Reflection Surface) tem por objetivo a obtenção de seções empilhadas e extração de parâmetros do meio geológico, através de análises de coerência com máxima utilização da redundância contida nos dados sísmicos de multicobertura. Para a realização dessas finalidades, o método CRS utiliza "superfamílias" de pares de fontes e receptores arbitrariamente dispostos em torno de um ponto central e empilhamentos através de tempos de trânsito multi-paramétricos, realizados de forma automática em todos os traços e amostras temporais do dado de entrada. Neste sentido, o método CRS representa um significativo aprimoramento do clássico método CMP (Common Midpoint), o qual utiliza famílias de pares fonte-receptor na configuração CMP e empilhamentos mono-paramétricos aplicados a traços e amostras manualmente escolhidos pelo intérprete. A eliminação da restrição a famílias $C M P$ no empilhamento CRS, permite a plena utilização de todos os dados sísmicos disponíveis, que se traduz em seções mais limpas e com maior razão sinal/ruído. Além disso, o número maior de parâmetros obtidos pelo método CRS garante maior conteúdo de informações sobre o meio geológico, informações estas muito úteis para uma variedade de outras tarefas de processamento, imageamento e inversão de dados sísmicos.

\section{Introdução}

Um dos mais importantes passos na seqüência de processamento de dados sísmicos consiste do chamado empilhamento dos dados, com vistas à obtenção de imagens ou seções temporais das regiões de interesse. O termo "empilhamento" tem o significado de soma de dados sísmicos ao longo de curvas construídas com base em um ou mais parâmetros, os quais devem ser considerados como atributos de propagação do meio geológico. Os parâmetros devem ser determinados através da condição de que o empilhamento forneça alto valor de amplitude quando as curvas se ajustem a eventos de reflexão e baixo valor quando este não é o caso. O empilhamento tem como pré-condição a redundância na amostragem em subsuperfície, isto é, a região considerada deve ser alvo de iluminação simultânea por muitos pares de fontes e receptores.

No processamento convencional, os dados sísmicos são previamente separados em famílias CMP que consistem em traços oriundos de pares de fontes e receptores simetricamente localizados em relação a um ponto central fixo. A sigla CMP é utilizada, tanto para designar a família de pares e receptores simétricos quanto o correspondente ponto central fixo. Para cada família $C M P$, o empilhamento é realizado através de uma curva de tempo de trânsito mono-paramétrico, isto é, envolvendo um único parâmetro. Como resultados da aplicação do método, são obtidas a seção empilhada e a correspondente seção do parâmetro velocidade de NMO (normal moveout), ambas definidas para cada CMP e amostra temporal.

Tendo em vista as atuais tecnologias de aquisição sísmica, capazes de produzir dados de cobertura muito mais densa e a custos mais baixos, bem como a disponibilidade de recursos de processamento mais poderosos, a restrição do empilhamento CMP a famílias de fontes e receptores simétricos tem se mostrado anacrônica. Uma solução adotada pelos pacotes sísmicos comerciais é a consideração de "superfamílias" $C M P$, que utilizam somas de dados referentes a algumas famílias CMP no entorno de uma família CMP de referência em alguns processos específicos, notadamente a análise de velocidades, não para o empilhamento final.

Com o objetivo de superar a restrição do empilhamento CMP a famílias de fontes e receptores simétricos, bem como a extração de apenas um parâmetro no processo de análise de velocidades, foi introduzido o método CRS. Com efeito, no método CRS é considerada para cada ponto fixo (chamado ponto central) uma "superfamília" de pares de fonte e receptor de localização arbitrária em relação ao ponto central. Para o empilhamento dos dados na superfamília é utilizada uma curva de tipo multiparamétrico, isto é, com mais de um parâmetro. A eliminação da restrição a famílias $C M P$ no empilhamento $C R S$, permite a plena utilização de todos os dados sísmicos disponíveis, que se traduz em seções mais limpas e com maior razão sinal/ruído. Além disso, o número maior de parâmetros obtidos pelo método CRS garante maior conteúdo de informações sobre o meio geológico, informações estas muito úteis para uma variedade de outras tarefas de processamento, imageamento e inversão de dados sísmicos.

Neste trabaho, descreveremos de forma sumária os métodos CMP e CRS, bem como comparações ilustrativas da aplicação dos dois métodos. Algumas conclusões e perspectivas finalizam o trabalho.

\section{O método CMP}

O método $C M P$ foi projetado visando produzir seções simuladas em afastamento nulo (seções empilhadas), de boa qualidade sinal/ruído ( $\mathrm{S} / \mathrm{N})$, bem como extrair um parâmetro de empilhamento, denominado velocidade 
NMO. O empilhamento utiliza tão somente os dados sísmicos de entrada na configuração $C M P$, daí o nome do método.

O empilhamento consiste basicamente das seguintes etapas: (a) Reorganização dos dados no domínio CMP; (b) Correção de tempo de trânsito $N M O$ e (c) Soma (empilhamento) dos traços pertencentes ao mesmo CMP. Um subproduto dessa técnica é a obtenção de um mapa de velocidades $N M O$

As premissas teóricas segundo as quais a correção NMO deve dar os melhores resultados são as de que o meio geológico seja constituído de camadas razoavelmente planas, com mergulhos pequenos e onde a velocidade de propagação não varie muito lateralmente na região em subsuperfície amostrada pelas trajetórias que compõem o CMP. A operação de empilhamento é executada no domínio CMP com base na velocidade NMO avaliada para alguns CMPs e alguns eventos (reflexões) selecionados pelo usuário ou intérprete.

Para cada evento selecionado, a correspondente velocidade $N M O$ é estimada por meio de análises de coerência de um único parâmetro. Este processo é conhecido na literatura como Análise de Velocidades. O mapa completo da velocidade NMO resulta da interpolação apropriada, no tempo e posição do $C M P$, das velocidades NMO previamente obtidas.

\section{Equação do tempo de trânsito NMO}

Consideramos a situação 2D, em que os pares de fonte e receptor estão situados em uma única linha sísmica, com refletores supostamente horizontais, e que as variações de velocidades e das estruturas em subsuperfície sejam restritas ao plano vertical que contém a linha. Dado um CMP com coordenada $x_{m}$ contendo uma reflexão com tempo de trânsito no afastamento nulo, $t_{0}$, a análise de coerência e a correção do NMO para esse evento são realizadas usando a equação de tempo de trânsito

$$
t(h)^{2}=t_{0}^{2}+C h^{2} \text {, }
$$

onde o parâmetro $C$ está relacionado com a chamada velocidade $N M O$,

$$
C=\frac{4}{v_{N M O}^{2}} \text {. }
$$

Como função do meio-afastamento, $h$, o tempo de trânsito, $t(h)$, representa a aproximação hiperbólica de segunda ordem do tempo de trânsito ao longo do raio de reflexão que conecta o par fonte-receptor, $\left(x_{m}-h ; x_{m}+h\right)$, da família CMP na posição $x_{m,}$, ao ponto em profundidade correspondente à reflexão analisada.

O método de empilhamento CMP é parte integrante de praticamente todas as seqüências de processamento sísmico, possuindo também abundante literatura. Para uma descrição geral e considerações práticas da técnica CMP, o leitor pode consultar, por exemplo, Yilmaz (2000). Como observado anteriormente, lembramos que 0 empilhamento de uma família CMP segundo o tempo NMO da Equação (1), fornece melhores resultados quando o meio é constituído de camadas com pequenos mergulhos e variação lateral de velocidade não muito acentuada. Para casos onde essas premissas não ocorrem, uma correção adicional ao tempo de trânsito deve ser considerada. Esta correção, denominada DMO (Dip Moveout), foge, no entanto ao escopo deste trabalho, sendo o leitor referido novamente ao trabalho de Yilmaz (2000).

\section{O Método CRS}

Em anos recentes, as premissas para o empilhamento $N M O$, a saber: (a) sua limitação aos dados no domínio CMP, (b) eventos selecionados pelo intérprete e (c) extração de um único atributo (a velocidade NMO) dos dados, começaram a ser questionadas pela comunidade geofísica. Como uma resposta a estas limitações, algumas aproximações mais gerais aos problemas do empilhamento e a extração de parâmetros do tempo de trânsito dos dados multicobertura foram propostas.

$\mathrm{Na}$ literatura sísmica, as novas propostas são referidas como métodos independentes do macro modelo de velocidades ou orientadas diretamente pelos dados. A característica comum das novas propostas é a utilização de tempos de trânsito gerais que podem empilhar dados de pares fonte-receptor que pertençam a um maior número de domínios, isto é, o empilhamento pode extrapolar o domínio CMP. O método CRS é uma delas.

Da mesma forma que o método $C M P$, o método $C R S$ em afastamento nulo destina-se a empilhar dados sísmicos de reflexão para produzir uma seção simulada de afastamento nulo (ZO), porém de forma independente do macro-modelo de velocidades fornecido pelo usuário.

Em contraposição ao método $C M P$, o método CRS utiliza uma equação de tempo trânsito multiparamétrica. Esta equação representa uma extensão natural do tempo de trânsito NMO dado pela Equação (1), chamada de tempo hiperbólico geral. O tempo de trânsito hiperbólico geral é válido para configurações arbitrárias de pares fontereceptor numa vizinhança de um dado ponto $x_{0}$, denominado ponto central. Na maioria dos casos, o ponto central é simplesmente uma posição CMP. Tendo em vista a aceitação de pares fonte-receptor de localizações arbitrárias relativamente ao ponto central, o método CRS empilha uma quantidade significativamente maior de traços que o método CMP. Isto explica o caráter mais bem definido e claro das seções CRS.

Da mesma maneira que o método CMP, um dos resultados do método CRS é seção ZO simulada. Entretanto, ao contrário do método CMP que produz um único parâmetro para cada família $C M P$, o método de CRS produz, na situação $2 \mathrm{D}$, um trio de parâmetros para cada família CRS, sendo esta definida por traços oriundos de fontes e receptores de localização arbitrária em relação ao ponto central. Para uma descrição geral de métodos independentes do macro modelo de velocidades, o leitor pode-se referir a Hubral (1999).

\section{Tempo de trânsito hiperbólico}

No caso de uma linha sísmica horizontal, se o ponto ZO estiver localizado pela coordenada $x_{0}$ na linha sísmica, se $v_{0}$ é a velocidade do meio no ponto em questão, e $x_{m}$ é o ponto médio do par fonte-receptor avaliado, o tempo de trânsito (geral) hiperbólico pode ser escrito como

$$
t\left(x_{m}, h\right)^{2}=\left[t_{0}+A\left(x_{m}-x_{0}\right)\right]^{2}+B\left(x_{m}-x_{0}\right)^{2}+C h^{2} \text {. }
$$


Pode-se notar que o tempo de trânsito hiperbólico depende de três parâmetros $A, B$ e $C$, designados como "parâmetros CRS" e definidos para cada posição ZO, $x_{0}$, e tempo de trânsito, $t_{0}$.

Interpretação dos parâmetros CRS: Os parâmetros $A$, $B$ e $C$ na expressão do tempo hiperbólico acima podem ser convenientemente interpretados da seguinte maneira. Denotando por $v_{0}$ a velocidade do meio no ponto central, $x_{0}$, o parâmetro A é dado por

$$
A=\frac{2 \sin \beta}{v_{0}},
$$

onde $\beta$ representa o ângulo que o raio $\mathrm{ZO}$ faz com a normal da superfície em $x_{0}$ (ver Figura 1(a)). Além disso, os parâmetros $B$ e $C$ são dados pelas expressões

$$
B=\frac{2 t_{0} \cos ^{2} \beta}{v_{0} R_{N}} \text { e } C=\frac{2 t_{0} \cos ^{2} \beta}{v_{0} R_{N I P}} \text {, }
$$

onde $R_{N}$ e $R_{\text {NIP }}$ são, respectivamente, os raios de curvatura das chamadas ondas $N$ e NIP, introduzidas por Hubral (1983). As ondas N e NIP são ondas fictícias que partem do refletor no tempo zero em uma vizinhança do ponto NIP (Normal Incidence Point) e se propagam para cima com velocidade igual à metade da velocidade do meio. O ponto NIP representa o ponto de incidência do raio normal a partir do ponto central $x_{0}$ em superfície. $O$ raio normal é aquele que tem incidência normal no refletor. A onda $N$ (ou onda Normal) é caracterizada por uma frente de onda coincidente com o refletor na vizinhança do ponto NIP. De maneira análoga, a onda NIP é definida como aquela que se inicia como uma fonte pontual no ponto NIP

Para uma malha de pontos predeterminados $\left(x_{0}, t_{0}\right)$, o método de $C R S$ produz mapas dos parâmetros $A, B$ e $C$, bem como a correspondente seção ZO simulada $u=u\left(x_{0}\right.$, $\left.t_{0}\right)$ e a seção de coerência $c=c\left(x_{0}, t_{0}\right)$. É fácil verificar agora que o tempo de trânsito NMO da Equação (1) é um caso particular do tempo geral hiperbólico da Equação (2) no caso de configuração CMP centrada em $x_{0}$. Podemos assim encontrar a relação que descreve a velocidade NMO em função dos parâmetros CRS, a saber, $V_{N M O}^{2}=\frac{4}{C}=\frac{2 v_{0} R_{N I P}}{t_{0} \cos ^{2} \beta}$.

Vale observar ainda, que se a velocidade, $v_{0}$, em torno do ponto central, $x_{0}$, é conhecida, e tendo em vista que o tempo ZO, $t_{0}$, é considerado dado no processo de busca dos parâmetros, o método CRS fornece os parâmetros $\beta$, $R_{N}$ e $R_{\text {NIP }}$, diretamente a partir dos parâmetros originais $A, B$ e $C$ (ver Equações (4) e (5)).

\section{Procedimento para a procura dos parâmetros CRS}

A busca dos três parâmetros CRS pode ser realizada, em princípio, em uma etapa só, com busca simultânea em todos os dados multicobertura. Não obstante, isto requer um alto custo computacional, mesmo nos sistemas computacionais de hoje em dia. Por essa razão, Müller et al. (1998) sugerem executar três buscas, procurando um parâmetro por vez. Esta estratégia não requer uma suposição inicial dos parâmetros, mas os limites para a procura devem ser definidos pelo usuário. Opcionalmente, uma otimização local pode ser executada no domínio tridimensional dos atributos, a partir do trio inicial constituído pelos parâmetros estimados nas etapas anteriores. Desta forma, os valores otimizados são obtidos posteriormente ao processo de busca inicial através de uma única etapa adicional (denominada de refinamento), com um custo computacional menor. As três etapas que definem o trio de parâmetros iniciais são:

Primeira Etapa - Busca do parâmetro C: Esta etapa é chamada empilhamento CMP Automático e é realizada com o auxílio da Equação (1) (tempo NMO), realizada para cada amostra temporal, $t_{0}$. No trabalho original de Muller et al. (1998), a velocidade $v_{0}$ é suposta conhecida, sendo a busca realizada para estimar o chamado parâmetro combinado, $q$, dado por $q=\frac{v_{0} C}{2 t_{0}}=\frac{\cos ^{2} \beta}{R_{N I P}}$.

Após a determinação da seção do parâmetro combinado, $q=q\left(x_{0}, t_{0}\right)$, realiza-se o empilhamento dos dados na configuração CMP, obtendo-se como resultado uma primeira seção simulada (empilhada) ZO. Observe a semelhança entre esse procedimento e o método CMP. Vale salientar, entretanto, que a determinação de parâmetros é realizada em todos os pontos centrais, $x_{0} \mathrm{e}$ em todas as amostras de tempo, $t_{0}$.

Segunda Etapa - Busca do parâmetro $A$ : Esta etapa pode ser chamada Busca de Onda Plana na seção ZO. A busca é feita no domínio ZO (seção obtida na primeira etapa). Para a determinação dos parâmetros, é utilizada equação do tempo de trânsito hiperbólico considerandose $h=0$, e supondo que $B=0$. Em outras palavras, a equação utilizada é linear e dada simplesmente por

$t_{\text {ZO }}^{\text {plana }}\left(x_{m}\right)=t_{0}+A\left(x_{m}-x_{0}\right)$.

Observe que, sendo conhecida a velocidade $v_{0}$ em $x_{0}$, o ângulo de emergência $\beta$ é imediatamente obtido pela expressão $\sin \beta=A v_{0} / 2$ (ver Equação (4)). Tendo em vista as obtenções dos parâmetros $q$ e $\beta$, a inserção destes na Equação (7), fornece o parâmetro $R_{\text {NIP. }}$ Este é o procedimento original de Müller et al. (1998).

Terceira Etapa - Busca do parâmetro B: Esta etapa é chamada Busca hiperbólica na seção ZO. A busca é feita ainda no domínio ZO, isto é, considerando-se $h=0$, agora, porém, com a inserção do parâmetro A já obtido. Em outras palavras, a equação utilizada é dada por

$$
t_{\mathrm{ZO}}^{\text {hip }}\left(x_{m}\right)^{2}=\left[t_{0}+A\left(x_{m}-x_{0}\right)\right]^{2}+B\left(x_{m}-x_{0}\right)^{2} \text {. }
$$

Segundo o procedimento original de Müller et al. (1998), no qual a velocidade $v_{0}$ é conhecida, a inserção do parâmetro $B$ obtido, bem como do ângulo $\beta$ da etapa anterior na Equação (5), fornece o terceiro parâmetro $R_{N}$.

Empilhamento Inicial CRS: Uma vez estimados os três parâmetros $A, B$ e $C$, correspondentes ao ponto central $x_{0}$, à amostra temporal, $t_{0}$, é aplicado o empilhamento segundo a Equação (3), sendo o seu valor alocado ao 
ponto $\left(x_{0}, t_{0}\right)$. A seção assim obtida denomina-se seção empilhada inicial, terminologia esta empregada para enfatizar que os parâmetros obtidos através deste procedimento representam primeiras estimativas passíveis de refinamentos.

Empilhamento Otimizado CRS: As estimativas acima dos parâmetros $A, B$ e $C$, podem ser convenientemente utilizadas como valores iniciais para um processo de otimização envolvendo agora os três parâmetros simultaneamente. Este processo representa um refinamento da busca anterior com vistas a resultados mais precisos para os parâmetros. De posse dos parâmetros refinados, obtém-se o chamado Empilhamento Otimizado CRS. A descrição mais detalhada do refinamento dos parâmetros foge ao escopo do presente trabalho, sendo o leitor referido ao trabalho de Majana et al. (2003).

\section{Aplicação a Dados Reais}

Com o objetivo de ilustrar o método CRS descrito acima, apresentamos os processamentos de dois conjuntos de dados, processados pelos métodos CRS e CMP.

As Figuras 1 e 2 mostram os resultados do processamento de uma linha terrestre utilizando o método convencional CMP e o método CRS, respectivamente. $O$ processamento $C M P$ foi realizado pelo pacote ProMax, da empresa Landmark. O processamento CRS foi realizado com o programa desenvolvido no âmbito do Consórcio Wave Inversion Technology (WIT) do qual, como mencionado no Resumo deste trabalho, o Laboratório de Geofísica da Computacional (LGC) da Unicamp é um dos membros. Sem entrar em maiores detalhes de interpretação das seções, podemos observar que o método CRS fornece seções mais limpas e com maior relação Sinal/Ruído, ocasionado pelo maior número de traços empilhados. Isto permite observar melhor a continuidade dos eventos de reflexão. Nota-se também, a melhor visualização das estruturas na parte superior da seção (até os 2000ms). Tais estruturas, na seção convencional $C M P$, não são facilmente identificadas devido ao alto nível de ruído.Outro exemplo de comparação, numa linha marítima, entre o método $C M P$ e o método CRS é apresentado, respectivamente, nas Figuras 3 e 4. Para a obtenção dessas seções, os mesmos pacotes de processamento do exemplo anterior foram utilizados. Nota-se que, como visto nas seções anteriores (Figuras 1 e 2), o método CRS apresenta uma seção mais limpa com melhor relação Sinal/Ruído. Na seção da Figura 4, os refletores profundos (abaixo de 1800ms e no intervalo de CMPs 390 a 90) estão mais evidenciados.

\section{Conclusões}

Os resultados do processamento através do método CRS, quando comparados com os dados sísmicos processados pelo método $C M P$, mostraram significativa melhoria de qualidade. Note-se a melhor definição e continuidade dos eventos na seção CRS quando comparados com os obtidos pelo método CMP.

A característica marcante do método CRS de utilizar a plena dos dados multicobertura disponíveis faz com que o método tenha grande potencial nos casos onde a cobertura não é grande. Esta é a situação, por exemplo, de muitos levantamentos terrestres, ou de reprocessamento de dados antigos. A experiência do Laboratório de Geofísica Computacional da Unicamp mostra que a utilização de metodologias de processamento de tecnologia mais avançada, como a do presente método CRS, permite o reprocessamento com qualidade muito superior à original. Esta observação tem relevância especial quando se consideram áreas nas quais uma nova aquisição não pode ser mais realizada.

Devido ao fato de ser um método recente, não são disponíveis ainda comparações sistemáticas entre seções de dados reais provenientes das aplicações dos métodos CMP e CRS. O crescente uso do CRS deverá prover essa lacuna, indicando com mais precisão as vantagens e desvantagens interpretativas das seções obtidas pelos métodos CMP e CRS, bem como o melhor benefício que se pode obter de ambas as tecnologias.

\section{Agradecimentos}

Agradecemos ao Conselho Nacional de Desenvolvimento Científico e Tecnológico (CNPq - Proc. 303065/2004-4), Petrobras (pela permissão de publicação dos dados sísmicos das figuras), empresas patrocinadoras do Consórcio Wave Inversion Technology e empresas Landmark Graphics Company (Strategic University Alliance, Grant 2002-COM-014331) e Paradigmgeo, pelo apoio e acordos educacionais de utilização de pacotes sísmicos no Laboratório de Geofísica Computacional (LGC) da Unicamp.

\section{Referências}

Hubral, P., 1999, Macro-model independent seismic reflection imaging: J. Appl. Geophysics, 42, no. 3, 4.

Majana, F., Mascarenhas, W., Tygel, M. and Santos, L.T., 2003, Refinement step for parameter estimation in the CRS Method: Rev. Bras, Geof., Vol. 21, no. 3, 275-287.

Mann, J., Hubral, P., Hoecht, G., Jaeger, R., and Mueller, T., 1999, Applications of the Common-Reflection-Surface stack: 69th Annual Internat. Mtg., Soc. Expl. Geophys., Expanded Abstracts, 1829.1832.

Muller, T., Jaeger, R., and Hoecht, G., 1998, Common Reflection Surface Stacking Method - Imaging with an unknown velocity model: 68th Annual Internat. Mtg., Soc. Expl Geophys., Expanded Abstracts, 1764-1767.

Tygel, M., Gamboa, F., Nunes, R. e Guerra, C., 2005, Empilhamento sísmico com máximo aproveitamento de dados multicobertura: O método CRS: Petro \& Química, 28 , no. $271,77-81$

Yilmaz, O., 2000, Seismic data analysis, in Cooper, M. R. and Doherty, S. M., Ed., Seismic Data Analysis Vol. 1, 01: Soc. of Expl. Geophys. 1000 p. 


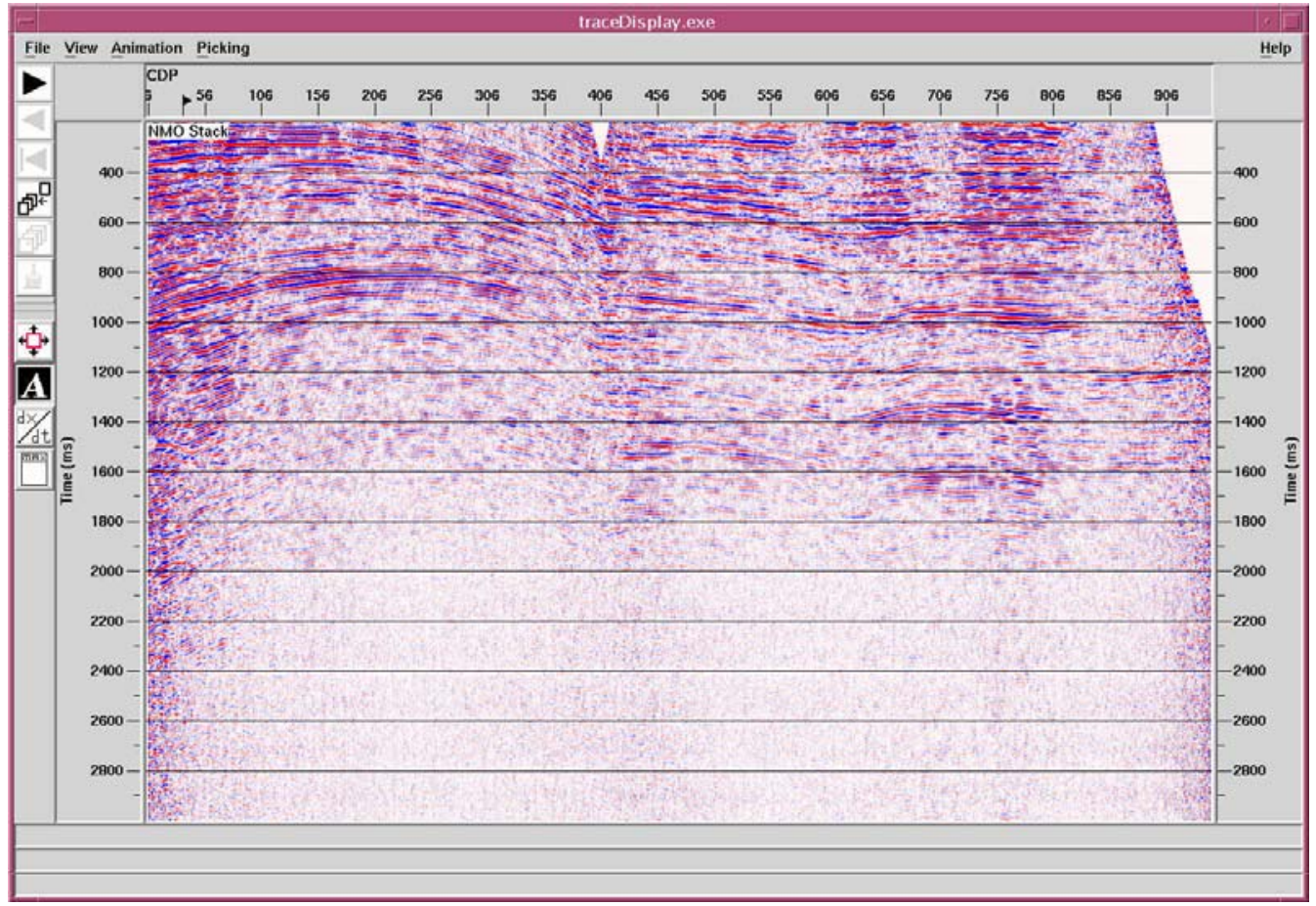

Figura 1: Seção de afastamento nulo simulada pelo método CMP

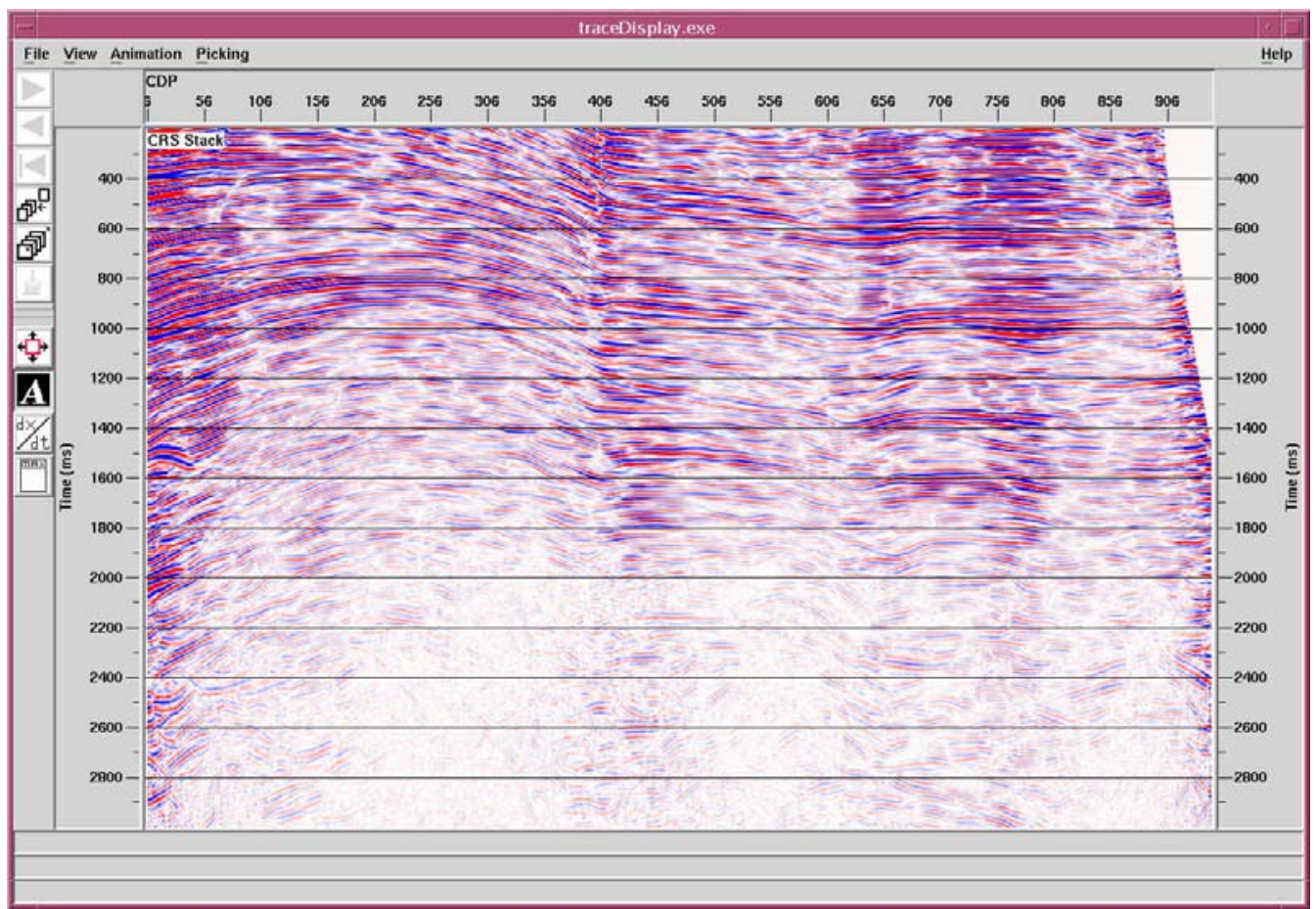

Figura 2: Seção de afastamento nulo simulada pelo método CRS. 


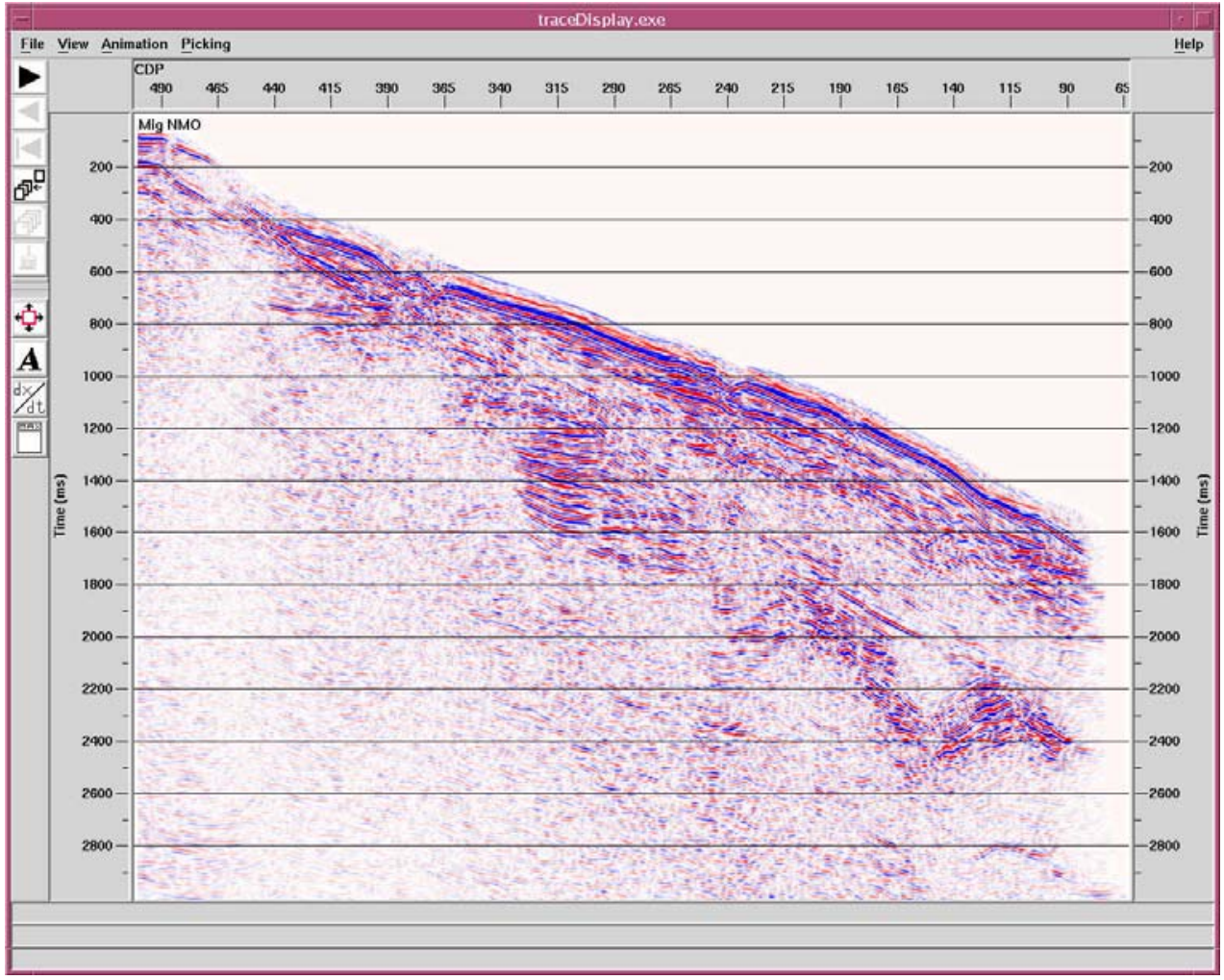

Figura 3: Seção de afastamento nulo simulada pelo método CMP.

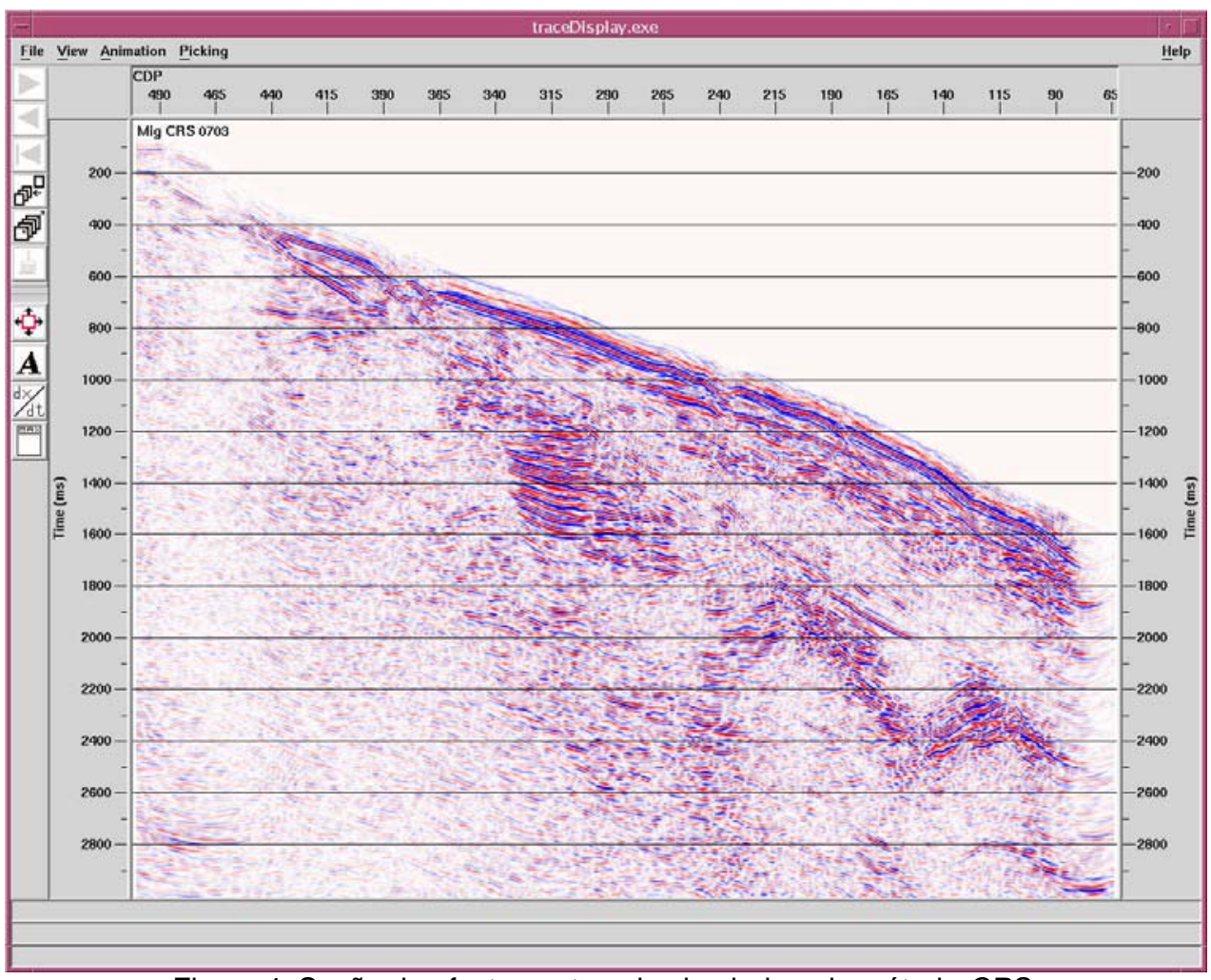

Figura 4: Seção de afastamento nulo simulada pelo método CRS. 